\title{
Promoting Efficiency and Competition in Rural Petrol Markets
}

\author{
Tom Murphy, Greg Walker and John Hicks
}

\begin{abstract}
A LMOST immediately after the report of the Commission of Inquiry into Retail Petrol Prices in Rural New South Wales (Parry, 1995) was published, the Australian Competition and Consumer Commission (ACCC) launched a similar inquiry with the publication of an issues paper in February 1996. The terms of reference of the inquiry included the 'need to assess the factors contributing to the significant variations between wholesale and retail petrol prices, particularly in rural Australia' (ACCC, 1996a:13). Following the Commonwealth election of March 1996, the new Treasurer, Peter Costello, in advising that the inquiry should continue, again referred to the need to investigate 'country petrol prices' (ACCC, 1996b:1). According to the Parry Report, the ACCC Inquiry is the 47th into petrol pricing since the establishment of the Prices Justification Tribunal (1973), the predecessor of the Prices Surveillance Authority, with 'much, though by no means all, of the focus of attention ... on the "problem" of retail petrol prices in rural areas' (Parry, 1995:1).

All these inquiries have addressed three key issues: whether there is a rural petrol price problem; the causes of any such problem; and the solutions to it. This article examines these issues by focusing on the findings and recommendations of three of the most recent inquiries, namely, the Industry Commission (IC) Inquiry of 1994, the Parry Inquiry of 1995, and the ACCC Inquiry, whose report was released in August 1996.
\end{abstract}

\section{Is There a Rural Petrol Price Problem?}

The three inquiries do not agree on the extent of the problem. The IC (1994:Appendix F, p. 5) judges that, for regions outside the populated coastal region of New South Wales, 'petrol prices . . . seem unreasonably high' and that the notional retail margin (the gap between the average retail price and the maximum wholesale price) 'exceeded what could be considered to be a reasonable retail margin'. Similarly, the ACCC (1996b:83) maintains that '[a]n important feature of rural petrol prices is that variations exceed, often by a significant amount, differences in freight differentials and State/Territory franchise fees, implying that other factors are

Tom Murphy is the Director of the Regional Economics Research Unit, Greg Walker is the Head of the School of Marketing and Management and John Hicks is the Dean of the Faculty of Commerce at Charles Sturt University. 
involved'. In contrast, Parry (1995:1) concludes that, while the rural petrol price problem is an 'important and, often, controversial issue for many people', its extent is exaggerated.

Parry's conclusion relies heavily on a study that used data derived from charge card transactions (Parry, 1995: Attachment 1). This study shows that metropolitan prices can vary significantly both within and between different areas, that metropolitan prices are more volatile than rural prices, and that average prices in the lower North Shore metropolitan area of Sydney were higher than average rural prices during the survey period: a point on which Parry places great emphasis.

Yet Parry admits (1995:28) that fuel card margins do not necessarily reflect normal margins and that the use of such cards 'appears to be more prevalent in the country'. Moreover, his emphasis on the lower North Shore finding seems inconsistent with his claim that the appropriate comparison should be with 'average metropolitan prices overall' (1995:2). Closer examination reveals that the data cited in the lower North Shore area are drawn from only four outlets, one of which recorded an extremely high price that ranged from five cents to nine cents a litre above that of its local competitors. If this one outlet is removed from the data, then the average lower North Shore figure is reduced sufficiently to throw doubt upon Parry's conclusion. Again, a substantial rural price differential emerges if, instead of comparing this one high-price urban area with an average of all rural areas, including low-price rural regions, one compares the lower North Shore area with the rural locations that are separately identified in Parry's own Attachment 1, namely, Tamworth, Armidale, Coonabarabran, Albury, Wagga Wagga, Bathurst, Orange and Dubbo. All of these rural areas reveal higher average prices than the lower North Shore area, both with and without the extreme single-outlet example.

Parry uses the finding of greater volatility in Sydney area prices to argue that comparisons should be based on data averaged over an extended period of time as well as a wide range of Sydney locations. His Attachment 2 cites alternative data, reproduced from the Service Station Association Ltd's submission to the Parry Inquiry, that give both average Sydney prices and average rural area prices for some rural towns and regions for a period of over eight months as well as the ACCC (PSA) maximum wholesale price and freight differentials for each region. Notional retail margins can be calculated from the difference between the retail price and the maximum wholesale price. The data show an average Sydney price of approximately 66 cents a litre, with a stated average notional retail margin of only 0.01 cents a litre (Parry, 1995:53). This compares with an average retail price of 76 cents a litre and an average notional margin of eight cents a litre for the rural locations of Armidale, Mudgee, Tamworth, Wagga Wagga, Far South Coast, and Far North Coast. Although the rural data are selective, they cover a wide range of rural locations and indicate a significant difference between rural and Sydney prices. This simple comparison, using Parry's own data and own recommended approach, provides a significantly different picture from Parry's. These rural margins are also much higher than the three to four cents a litre reported for the charge card data in 
Parry (1995:Attachment 1), thus supporting the view that charge card data understate normal rural margins.

Corroborative evidence of a significant price difference between metropolitan and rural areas is provided by the IC (1994) and the ACCC (1996b). Using the NSW survey data cited by the IC (1994) supplied by the National Roads and Motorists Association and the NSW Local Government and Shires Association, Murphy, Walker and Hicks (1996) note that in some rural locations the average retail price was a significant 9.64 cents a litre, or 14.1 per cent, higher than average metropolitan retail prices, whereas four rural locations had lower than average rural retail prices. In each of the latter, the lower prices can be explained by the unique characteristics of the markets concerned. For example, Lismore's prices are influenced by its proximity to Queensland and a consequent exemption from the State franchise fee; Coffs Harbour enjoys a 40 per cent reduction in the State franchise fee; and prices in Maitland and Nowra are influenced by their proximity to the competitive metropolitan markets of Newcastle and Wollongong. Parry, however, seems to have ignored the IC's distinction between rural areas and the greater metropolitan coastal region of NSW.

Other surveys and submissions made to the ACCC inquiry report significant rural price differentials, with the exception of the Shell oil company's submission for Victorian country petrol, in which a similar finding to that of the NSW greater metropolitan area is evident. The ACCC notes that, whereas the Shell submission implies 'that country prices are not out of line with city prices' (ACCC, 1996b:82), if Geelong is excluded from the eleven listed Victorian country centres its own analysis of the Shell data finds an average differential of 7.3 cents a litre, as opposed to Shell's 4.3 cents a litre. The ACCC (1996b:82) also reports the results from a survey of service station accounts, conducted by the authors of this article, and presented in the Orana Regional Development Board's submission to the inquiry, that found that average prices for a select number of rural outlets with moderate sales volume in a large rural town were up to 8.8 cents a litre higher than average city prices.

In our opinion, Parry's conclusion that the rural petrol price problem is exaggerated does not withstand scrutiny.

\section{Causes of the Rural Price Problem}

Parry does, however, concur with the IC's view that, to the extent that any problem does exist, so-called local factors are primarily responsible. According to this explanation, retail margins in rural areas are higher because: rural communities have too many service stations and existing retailers therefore lack access to economies of scale; insufficient investment in the industry results in inefficient rural distribution networks; rural service stations have fewer ancillary operations, such as shops and car washes, that subsidise revenues from city petrol sales; and, for some rural markets, the pricing pattern indicates tacit collusion.

This explanation focuses exclusively on cost structures and horizontal competitiveness among retailers. The latter involves the claim that, as retailers in the more 
competitive metropolitan markets have a higher price elasticity than retailers in rural markets, they have a stronger incentive to lower prices and compete than do rural retailers. But government regulation of the structure and behaviour of this industry surely plays a role. The regulation reflects the fact that, as the oil industry is an oligopoly controlling a strategic product that virtually every Australian business and household needs, the oil majors have considerable market power and an incentive to collude.

For example, the current intervention pricing system operates under the regulatory power of the Prices Surveillance Act. The four major oil companies are declared under this Act and hence required to notify formally the ACCC of proposals to increase their wholesale prices. The ACCC will endorse the wholesale price charged for petrol (and distillate) by each company provided the prices are at or below indicator price levels calculated by the ACCC (see IC, 1994:4-5). The prices notified by each company (if they do not exceed the indicator price) become the basis on which prices are capped throughout the country. The wholesale price for each capital city with a refinery is calculated by adding the relevant State or Territory franchise fee. For other locations, the ACCC-determined freight differential must also be added.

The Petroleum Retail Marketing Franchise Act 1980 (Franchise Act), which sets minimum conditions for retail franchise agreements, is an attempt to address directly the imbalance in negotiating power between retailers and the oil majors. The Act effectively gives the franchisees nine years' tenure. The oil majors argue that this provision substantially inhibits restructuring of the industry. As the Act made it more attractive for the oil majors to own and operate their own outlets, the Petroleum Retail Marketing Sites Act 1980 (Sites Act) was introduced in order to reinforce the Franchise Act by limiting the number of retail sites owned and operated by the oil majors. Whereas supporters of the Sites Act argue that its provisions help to limit the domination of the retail market by the oil majors, the oil companies claim that the Sites Act and, to a lesser extent, the Franchise Act inhibit investment and rationalisation in their rural retail networks (ACCC, 1996b:131).

Finally, the Laidely Agreement between the Transport Workers Union and the Australian Petroleum Agents and Distributors Association restricts the access of independents to the terminals of the oil majors by providing for the transport of fuel from these terminals by carriers who are signatories to the agreement.

The intervention pricing system, as the most controversial element of this regulatory package, has attracted close attention from all three inquiries. In our view, it is a major contributing factor to the rural petrol pricing problem that adherents to the local-factors explanation overlook. The fundamental flaw in the system is the looseness of its settings. Metropolitan retailers, who make up the bulk of the market, are frequently charged several cents a litre less than the maximum wholesale price, usually through a system of price support rebates that are not available to rural retailers. This indicates that the 'market' wholesale price is often well below the ACCC maximum which rural retailers invariably pay in full. 
Using survey data to compare metropolitan and rural retailers, Murphy, Walker and Hicks (1996) show that average wholesale prices, after freight charges and oil company support are included, were 70.2 cents a litre for rural markets and 63.2 cents for metropolitan markets: a difference of seven cents a litre. Subtraction of the justifiable net freight difference of 1.4 cents a litre leaves an effective price subsidisation by the oil companies, in the form of lower average wholesale prices, of 5.6 cents a litre for metropolitan retailers.

The intervention pricing system thus provides a regulatory rationale for charging a wholesale price to rural retailers that is too high and certainly above the market price charged in the more competitive urban market. This conclusion is supported by the very low, and at times even negative, notional retail margins (based on maximum wholesale prices) for city retailers reported in Parry (1995) and IC (1994). Such margins are the result of city service stations being charged less than the maximum wholesale price, usually through price support rebates.

The current regulatory system also directly affects horizontal competitiveness in rural markets by encouraging and facilitating collusion. Each major and each retailer know that all retailers will be charged the maximum ACCC wholesale price. The collusive effect of knowledge of the cost structure of a large part of the industry chain is demonstrated by O'Brien and Shaffer (1993:220), who claim that 'selling to an independent agent when contracts are observable affords strategic commitment to higher retail prices'. Further, Lin $(1988,1990)$ and Bonanno and Vickers (1988) show that vertical separation (again with observable contracts) induces more friendly behaviour from a manufacturer's rivals. Collusion in metropolitan markets is not encouraged by this effect because the level of price support is confidential and contracts are therefore not observable.

Existing price regulations have thus not only failed to protect rural petrol consumers from the market power of the majors but have given the majors a platform on which to exercise that power.

In addition to payments for petrol, which is the object of the ACCC's price intervention, retailers pay oil majors rents, franchise fees, inspection fees, credit charges and brand fees. Such site charges (as we call them) are not controlled by the ACCC, even though the oil majors could use them as a means to exploit further their monopoly power and, specifically, to 'claw back' for themselves any additional profits that arise from any collusion or even investment by country retailers. ' Confidential interviews with retail and distributor operators drew attention to the oil majors' common practice of setting site charges well above the amount service stations could afford to pay and then allowing service stations to negotiate charge reductions. This practice allows oil majors to appropriate monopoly profits, leaving service stations with normal profits. Its effects have been examined in the literature on the 'renegotiation of franchise contracts'. According to Dewatripont and Sekkat

\footnotetext{
'The term 'clawback' and the process it describes were first outlined by the authors in submissions written for the Orana Regional Development Board to both the Parry and the ACCC Inquiries (see ACCC, 1996b).
} 
(1991:595), contracts are frequently quite imprecise concerning producer obligations and provide for significant ex post producer opportunism. Shaffer (1995:264) goes further and demonstrates that, for a monopoly, an appropriate two-part tariff (such as a wholesale petrol price and site fees) not only allows clawback but also makes retail price maintenance superfluous for profit maximisation.

Murphy, Walker and Hicks (1996) found that the rural stations were less profitable than the metropolitan stations, despite the evidence of higher rural retail petrol margins, mainly because metropolitan stations enjoy a greater income from other sources. Other expenses, apart from those paid to the oil companies, were roughly equal. Consistent with the general clawback thesis, it was the more profitable metropolitan stations that paid higher per-litre site charges to their oil companies. However, as the major component of the rural-metropolitan price differential was the higher wholesale price, the average overall payment to oil companies as a ratio of turnover was higher for the rural outlets (79 cents per dollar of turnover) than for metropolitan outlets ( 70 cents).

The presence of clawback and wholesale price discrimination make it impossible to dismiss the rural petrol pricing problem as an effect of exclusively local factors. The ACCC Inquiry goes further than any previous inquiry in acknowledging these non-local factors as key causes of the rural petrol price problem (ACCC, 1996b:94).

\section{Policy Recommendations}

The inquiries examined in this article all recommend deregulation of the Australian petroleum products industry. But they differ in important respects.

All three inquiries agree that the Sites Act has been ineffective and may have impeded industry rationalisation, and recommend its repeal. However, the ACCC (1996b:13) qualifies this view by claiming that the most important factor restraining site rationalisation is 'the general lack of effective competition between the oil companies'. Opinion on the Franchise Act is divided. Whereas the IC was convinced that its repeal would assist industry adjustment and that Oilcode, a process of industry self regulation which aims to set minimum standards for the conduct of supply agreements, was sufficient to act in its place, the ACCC argues that further development of the Oilcode should occur before the Franchise Act is replaced.

All three inquiries are concerned to ensure access to terminals. But whereas the IC advocates special Commonwealth legislation to remove the anti-competitive aspects of the Laidely Agreement, Parry and the ACCC conclude that the Agreement it is no longer a serious impediment to terminal access under current operating conditions. The ACCC (1996b:135) also warns that attempts 'to remove the Agreement could prove costly'.

The three inquiries also advocate abolition of the intervention pricing system. The IC (1994:xxiv) concludes that, as retail margins are the prime cause of the rural petrol price problem, wholesale price regulation is ineffective, and is irrelevant in competitive urban markets. Parry (1995:5) agrees that pricing regulation has been ineffective and therefore expresses reluctance to recommend further price regula- 
tion. The ACCC, however, recommends revocation of the oil industry declarations 'subject to it being satisfied that its concerns have been fully addressed'. This means that the ACCC recommendation is conditional on a number of competitive adjustments being delivered by the industry, including 'renegotiation of contracts, rationalisation of country retail sites and the development of imports as a viable, independent competitive force' (ACCC, 1996b:138). It envisages a transition period during which the ACCC would maintain the existing intervention pricing system and review other issues such as multi-site franchising, terminal entry for independents and tied supply agreements.

Whereas the IC (1994:xviii-ix) concludes that 'there is effective competition in most petroleum product markets most of the time' and that 'there is a continuing threat from imports', the ACCC (1996b) believes that the industry is highly concentrated at the refinery level and that competition currently provided by imports is inconsequential. However, it concedes that this is likely to change with the possible establishment of new import operations. These include: the sale of terminal facilities following the Ampol/Caltex merger and the possibility of other majors selling terminal sites as industry rationalisation proceeds; existing potential for the construction of new terminal sites; the availability on world markets of adequate stocks of fuel for importation at competitive prices; and an increased willingness by independents to import because of the failure of domestic refiners to supply at a competitive price.

The ACCC's clear message is that it does not believe the oil companies have been operating in a competitive manner and that any deregulation should be conditional on their helping to bring about changes in the industry that will enhance competition at all levels. For the rural retail sector, it suggests measures such as the formation of 'buying groups', including local governments, to develop alternative supply arrangements with petroleum product suppliers. It also expresses the hope that independents will spread to country areas as they seek out new markets.

\section{Conclusions}

Repeal of the Sites Act holds out the promise of greater investment in rural site restructuring and thus improved cost efficiency. But increased cost efficiency is not likely to translate into lower prices unless accompanied by competition; and the ACCC, unlike the $\mathrm{IC}$, is not convinced that the four oil companies are competitive. It believes that the oil companies have considerable market power (ACCC, 1996b:137) and little incentive to compete on price (ACCC, 1996b:127). To remedy this, it is mainly relying, not on price deregulation, but on a future increase in independents' penetration into the industry with increased sourcing of supply from imports. Yet the record of independents in Australia is not impressive (ACCC, 1996b:13) nor is the importation of fuel without significant difficulties (ACCC, 1996b:57). Moreover, even if the number of independents did increase, would they locate in small-volume rural areas in preference to city markets?

What sets the ACCC recommendations apart, however, is their conditional nature. In particular, the tantalising offer to the oil companies of pricing freedom 
which would not be delivered until the required competitive adjustments occurred in the industry. The ACCC has thus devised the most significant strategy to be proposed by any inquiry to address the rural petrol price problem. But, as in any strategic game, this should not preclude resort to other, as yet unspecified, measures should the preferred outcome not come to pass. The ACCC, with government backing, could still fall back on much stronger measures such as the re-regulation of prices, the divorce of retail from manufacturing ownership, the abolition of multisite franchising, and forced access to supply for independents. In the meantime, rural communities seeking a reduction in petrol prices should consider adopting the strategies suggested by the ACCC, like setting up buying groups, that will retain focus on the rural petrol price problem and assist the ACCC in ensuring that improved efficiency and pricing competition are delivered to rural as well as metropolitan Australia.

\section{References}

Australian Competition and Consumer Commission (ACCC) (1996a), Issues Paper for the Inquiry into the Petroleum Products Declaration, AGPS, Canberra.

(1996b), Inquiry into the Petroleum Products Declaration, AGPS, Canberra.

Bonanno, G. \& J. Vickers (1988), 'Vertical Separation', Journal of Industrial Economics 36: 257-65.

Dewatripont, M. \& K. Sekkat (1991), 'Producer Opportunism in Retailing Contracts', Journal of Industrial Economics 39(5): 595-620.

Industry Commission (IC) (1994), Petroleum Products, AGPS, Melbourne (July) (Report No. 40).

Larkin, J. \& T. Dwyer (1993), 'Monopoly and the Distribution of Petroleum Products', Canberra (unpublished paper).

Lin, Y. (1988), 'Oligopoly and Vertical Integration: Note', American Economic Review 78(1): 251-4.

- (1990), 'The Dampening of Competition Effect of Exclusive Dealing', Journal of Industrial Economics 39: 209-23.

Murphy, T., G. Walker \& J. Hicks (1996), 'Rural Petrol Pricing: A Critique of the Parry Inquiry', Faculty of Commerce, Charles Sturt University, Wagga Wagga (Working Papers in Economics).

O'Brien, D. \& G. Shaffer (1993), 'On the Dampening-of-Competition Effect of Exclusive Dealing', Journal of Industrial Economics 41 (2): 215-21.

Parry, T. (Commissioner) (1995), Commission of Inquiry into Retail Petrol Prices in Rural New South Wales (Pany Inquiry), Government of New South Wales, Sydney.

Shaffer, G (1995), 'On Vertical Restrictions and the Number of Franchises: Comment', Southem Economic Journal 62(1): 264-8.

This article is based on submissions written by the authors on behalf of the Orana Regional Development Board to the Australian Competition and Consumer Commission Inquiry into the Petroleum Products Declaration. They acknowledge the support and funding provided by the Board and the benefit they have received from the comments of the editor and two anonymous referees, but remain responsible for any errors. 